\title{
Lessons Learned from the Master of Space and Time: Leon Russell
}

\author{
Andy Gillentine \\ University of South Carolina \\ This paper was presented at the 2019 International Summit of the \\ Music \& Entertainment Industry Educators Association \\ March 21-23, 2019
}

\section{https://doi.org/10.25101/19.41}

\section{Abstract}

Leon Russell provided the musical soundtrack for many individuals over six decades in the music industry. His musical influence can be heard on records ranging from Frank Sinatra to the Rolling Stones. His potential influence however, does not end with the final notes of a song. Throughout his professional career, Leon Russell laid out a framework that could benefit not only future generations of music and entertainment performers and entrepreneurs, but also individuals looking to succeed in any segment of industry. This presentation will examine the personal and professional lessons demonstrated throughout the career of Leon Russell and present ways to implement these lessons into action. The information gathered for this project was collected from written interviews, recorded interviews, and video footage. Additional insight has been solicited from individuals who were associated personally and professional with Leon on the span of his career.

Keywords: Leon Russell, music industry education, entertainment industry education

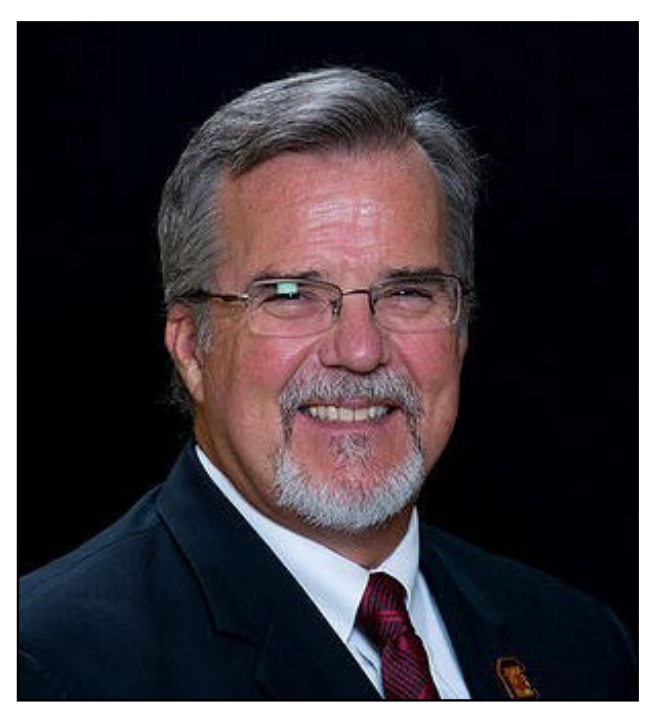

Andy Gillentine is a Professor in the Department of Sport and Entertainment Management at the University of South Carolina. In 2017, he was awarded the Sport Management Scholar Lifetime Achievement Award by the Applied Sport Management Association. He was named Distinguished Sport Management Educator in 2012 by the North American Society of Sport Management and in 2009 received the Sport Management Outstanding Achievement Award from the National Association of Sport and Physical Education. He is nationally recognized for his expertise in sport management curriculum and program development. $\mathrm{He}$ is recognized as one of the leading experts in the study of the legal, managerial, and marketing aspects of tailgating. He has conducted research projects for numerous sport organizations that have resulted in over fifty publications, four books, and over one hundred national and international presentations. 


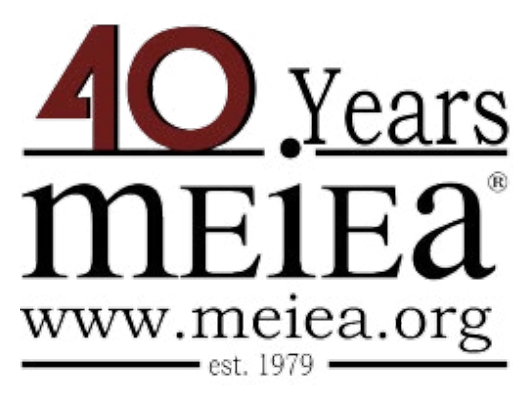

\section{PROCEEDINGS OF THE \\ 2019 INTERNATIONAL SUMMIT \\ OF THE \\ MUSIC \& ENTERTAINMENT \\ INDUSTRY EDUCATORS \\ ASSOCIATION}

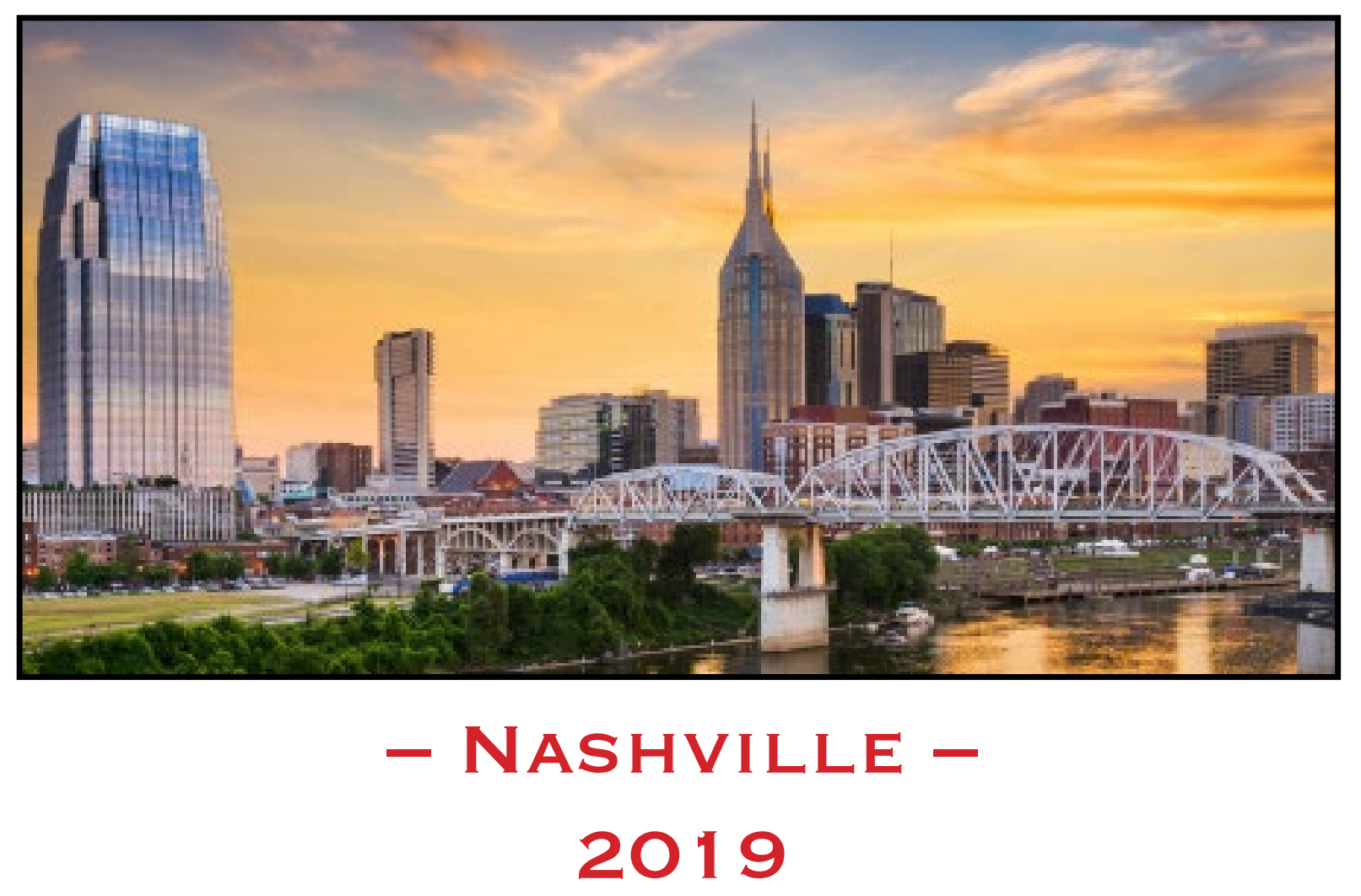

March 21 - 23, $2019 \cdot$ Belmont University - Nashville 